\title{
ANALISIS KELAYAKAN FINANSIAL USAHA FRANCHISE O'CHICKEN DI KELURAHAN SIMPANG TIGA KECAMATAN BUKIT RAYA KOTA PEKANBARU
}

\author{
Indah Marianju Nauli ${ }^{1}$, Yusmini $^{2}$, Susy Edwina $^{2}$ \\ Program Studi Agribisnis, Jurusan Agribisnis \\ Falkutas Pertanian Universitas Riau, Kode Pos 28293, Pekanbaru \\ Indahmarianjunauly.IMN@gmail.com
}

\begin{abstract}
Abstrak
Penelitian ini bertujuan untuk menganalisis kelayakan finansial dan kepekaan terhadap perubahan harga input dan output waralaba bisnis franchise O'Chicken di Kelurahan Simpang Tiga Kecamatan Bukit Raya Kabupaten Pekanbaru. Survei dilakukan pada bulan November 2017, untuk mengumpulkan data primer dan sekunder. Data dianalisis dengan menggunakan kriteria investasi yaitu NPV, Net B/C, IRR dan Pay Back Period. Hasil penelitian menunjukkan usaha ini secara ekonomi layak karena memiliki nilai NPV positif sebesar Rp.883.637.518,- Net B/C lebih besar dari satu yaitu 3,35, nilai IRR lebih besar dari Social Opportunity Cost of Capital (SOCC), dengan pengembalian investasi yang panjang atau Pay Back Period selama 4 tahun 3 bulan. Analisis sensitivitas terhadap kenaikan harga input bahan baku daging ayam adalah $31,60 \%$, dan penurunan skala produksi sebesar 11,21\% lebih besar dari break event point, jika kenaikan diatas persentase tersebut maka usaha ini tidak layak untuk dijalankan karena NPV $<0$.
\end{abstract}

Kata kunci: kelayakan finansial, usaha, waralaba, ayam organik

\section{PENDAHULUAN}

Pertumbuhan ekonomi merupakan masalah perekonomian dalam jangka panjang dan merupakan fenomena penting yang di alami dunia belakangan ini. Menurut Benjamin (2007) sebuah negara akan dinilai sukses apabila negara tersebut mampu menyediakan lapangan kerja, menurunkan kemiskinan serta meningkatkan taraf hidup manusia seperti di negara belahan Eropa dan Amerika Serikat. Namun, untuk menciptakan itu semua sebuah negara harus menciptakan iklim investasi yang baik, dan mampu mempercepat laju pertumbuhan ekonomi. Pertumbuhan ekonomi di Indonesia dalam kurun waktu tiga tahun mengalami peningkatan. Tercatat pertumbuhan ekonomi Indonesia pada tahun 2015 sebesar 4,88 persen, tahun 2016 sebesar 5,03 persen dan pada tahun 2017 sebesar 5,07 persen (BPS, 2018).

Perkembangan perekonomian di Indonesia juga didukung oleh perusahaan yang memberikan kontribusinya untuk pertumbuhan ekonomi Indonesia yang salah satu perusahaan tersebut adalah perusahaan ritel yang berbasis waralaba. Jenis bidang usaha waralaba ini bermacam-macam yang salah satunya yaitu usaha waralaba pada bisnis kuliner siap saji.

Usaha kuliner siap saji juga merupakan bagian dari usaha yang harus memperhatikan kepuasan terhadap konsumen. Setiap konsumen memiliki selera masing-masing yang dipengaruhi oleh gaya hidup dan pola kosumsi yang bergeser dalam mengikuti trend yang sedang terjadi dan berkembang. 169 | Analisis Kelayakan Finansial Usaha Franchise O'chicken Di Kelurahan Simpang Tiga

Kecamatan Bukit Raya Kota Pekanbaru 
Trend dapat merambat dengan cepat dengan cepat ke segala jenis kebutuhan manusia, salah satu trend yang sedang berkembang saat ini sering disebut dengan "back to nature". Salah satu elemen yang mendasari munculnya "back to nature" ialah pola hidup sehat yang akrab dengan lingkungan, telah menjadi trend baru dan telah melembaga secara internasional yang mengisyaratkan jaminan bahwa produk pertanian dan pertenakan yang menghasilkan bahan pangan harus beratribut aman dikonsumsi (food safety attributes), kandugan nutrisi tinggi (nutritional attributes), dan ramah lingkungan (ecolabelling attributes).

Munculnya pemikiran pola hidup sehat maka terciptalah makanan berlabel 'Organik', mulai dari sayur, buah, beras dan ayam organik. Ayam organik yaitu ayam yang diternakkan secara alami. Ayam organik biasa juga disebut dengan ayam herbal atau ayam probiotik adalah ayam boiler / ayam potong yang dibudidaya dan setelah menetas hingga panen dengan menggunakan pakan khusus (jagung, dedak, tepung ikan, dll) Sehingga bisnis waralaba (franchise) yang menggunakan pola hidup sehat berbasis organik adalah franchise O'Chicken.

Usaha kuliner franchise O'Chicken merupakan usaha bisnis waralaba yang berkembang di Kota Pekanbaru sejak tahun 2015. Usaha ini memiliki 7 outlet yang tersebar di Kota Pekanbaru yaitu di Kecamatan Tampan, Kecamatan Payung Sekaki, Kecamatan Tenayan Raya, Kecamatan Sail, Kecamatan Rumbai, Kecamatan Sidomulyo dan Kecamatan Bukit Raya. Outlet franchise O'Chicken di Kecamatan Bukit raya merupakan outlet yang memiliki sakala usaha terbesar dibandingkan outletoutlet yang lainnya. Kuliner ini menyediakan menu makanan yang siap saji seperti ayam goreng organik, tomyam, burger, kentang goreng dan sup ayam organik. Kuliner ayam organik di franchise O'Chicken ini mempunyai tempat yang cukup besar dengan meja dan kursi yang tersusun rapi dan nyaman. Fasilitas yang tersedia di usaha ini merupakan bentuk pelayanan/service kepada para konsumen agar konsumen merasa puas dan nyaman saat berada di franchise O'Chicken.

Berdasarkan hasil pengamatan dilapangan, seiring dengan prospek pasar yang bagus masyarakat semakin menyukai mengkonsumsi O'Chicken ini sehingga produsenpun meningkatkan produksinya. Oleh karena itu usaha ini perlu dilakukan perhitungan aspek finansial untuk pengembangan usahanya dimasa yang akan datang. Aspek finansial ini dapat dilihat dari biaya-biaya yang digunakan selama operasional usaha serta pendapatan yang diperoleh.

Adapun tujuan penelitian ini adalah (1) Menganalisis kelayakan finansial usaha franchise O’Chicken di Kelurahan Simpang Tiga Kota Pekanbaru dan (2) Mengetahui pengaruh perubahan harga input dan output terhadap kelayakan finansial usaha franchise O'Chicken di Kelurahan Simpang Tiga Kota Pekanbaru.

170 | Analisis Kelayakan Finansial Usaha Franchise O'chicken Di Kelurahan Simpang Tiga Kecamatan Bukit Raya Kota Pekanbaru 


\section{METODE PENELITIAN}

\section{Tempat dan Waktu Penelitian}

Penelitian ini dilaksanakan di franchise O'Chicken di Kelurahan Simpang Tiga Kecamatan Bukit Raya Kota Pekanbaru pada Bulan November 2017.

\section{Metode Pengambilan Data}

Metode yang digunakan dalam penelitian adalah metode studi kasus dengan mengadakan pengamatan langsung di lapangan, mencari informasi kepada informan, yaitu pengusaha, manajer dan karyawan uasaha francise O'Chicken dengan menggunakan kuesioner sebagai alat bantu.

\section{Jenis Data}

Data yang digunakan dalam penelitian terdiri dari data primer dan data sekunder, dimana data primer diperoleh berupa data langsung yang dilakukan dengan cara observasi dan wawancara dengan pemimpin atau manajer usaha franchise O'Chicken dan karyawan bagian produksi, dengan menggunakan kuesioner yang berupa data biaya investasi, dan data biaya operasional yaitu biaya sewa bangunan, pembelian bahan baku, biaya komunikasi, biaya listrik, biaya transportasi, biaya keamanan, biaya perawatan, biaya kebersihan dan upah tenaga kerja. Sedangkan data sekunder diperoleh dari instansi terkait yaitu Badan Pusat Statistik, Dinas Perindustrian dan Perdagangan Kota Pekanbaru.

\section{Analisis Data}

Analisis yang dilakukan dalam penelitian ini adalah analisis kuantitatif, yaitu analisis kelayakan finansial usaha franchise O'Chicken di Kelurahan Simpang Baru. Analisis kelayakan finansial ini menggunakan perhitungan kriteriakriteria investasi antara lain Net Present Value (NPV), Internal Rate Return (IRR), Net Benefit Cost Ratio (Net B/C Ratio), dan analisis sensitivitas.

\section{Tingkat Inflasi}

Inflasi adalah suatu proses meningkatnya harga - harga secara umum dan terus - menerus (kontinu) berkaitan dengan mekanisme pasar yang dapat disebabkan oleh faktor - faktor tertentu (Muchtar et al, 2016). Analisis tingkat inflasi digunakan untuk proyeksi biaya dimasa yang akan datang pada beberapa koefisien teknis lainnya seperti perhitungan biaya reinvestasi peralatan, biaya operasional, proyeksi harga input dengan menggunakan rata - rata tingkat inflasi sebesar $6,67 \%$. 


\section{Discount Factor}

Discount Factor adalah menghitung nilai sekarang dari nilai uang yang akan datang jika diketahui besarnya tingkat bunga dan lamanya periode (Pasaribu, 2012). Rumus discount factor adalah:

Dimana:

$$
P=F \frac{1}{(1+i)^{n}}
$$

$\mathrm{P}=$ Nilai sekarang $(\mathrm{Rp})$

$\mathrm{F}=$ Nilai uang yang akan datang $(\mathrm{Rp})$

$\mathrm{I}=$ Tingkat bunga (12\%, merupakan rata - rata tingkat suku bunga bank yang berlaku di

Kecamatan Bukit Raya)

$\mathrm{N}=$ Umur usaha franchise O'Chicken

\section{Biaya penyusutan}

Biaya penyusutan adalah biaya yang dibebankan pada konsumen melalui perhitungan harga pokok produksi. Biaya penyusutan juga dianggap sebagai laba dalam perhitungan rugi karena dan yang disisihkan sebenarnya merupakan penerimaan penguasaha yang dapat digunakan pada berbagai kepentingan. Metode penyusutan dalam penelitian ini menggunakan metode garis lurus ( straight line method ), dikarenaka umur ekonomis pada usaha belum habis tetapi umur proyeksi usaha franchise O’chicken sudah selesai. Rumus biaya penyusutan adalah:

$$
\mathrm{P}=(\mathrm{B}-\mathrm{S}) / \mathrm{n}
$$

Dimana :

$\mathrm{P} \quad=$ jumlah penyusutan per tahun (Rp/tahun).

$\mathrm{B} \quad=$ harga beli peralatan (Rp/tahun).

$\mathrm{S} \quad=$ nilai sisa $(\mathrm{Rp} / \mathrm{tahun})$

$\mathrm{n} \quad=$ umur ekonomis peralatan

\section{Analisis Kriteria Investasi}

a. Net present value(NPV)

Net Present Value (NPV) adalah nilai sekarang dari arus pendapatan yang ditimbulkan oleh investasi pada tingkat bunga tertentu. Rumus yang digunakan dalam penghitungan NPV adalah sebagai berikut :

$$
\mathrm{NPV}=\sum_{t=0}^{n}(B t-C t) /(1+i)^{t}
$$

\section{Dimana:}

$\mathrm{B}_{\mathrm{t}}=$ Benefit dalam usaha franchiseO'Chicken pada tahun ke-t (Rp/tahun)

$\mathrm{Ct}=$ Biaya total yang dikeluarkan dalam usaha franchiseO'Chicken

pada tahun ke-t (Rp/tahun)

$\mathrm{n}=$ Umur ekonomis usaha (tahun)

172 | Analisis Kelayakan Finansial Usaha Franchise O'chicken Di Kelurahan Simpang Tiga

Kecamatan Bukit Raya Kota Pekanbaru 
$\mathrm{i}=$ Compound rate atau tingkat suku bunga $(\%)$

$\mathrm{t}=$ Tahun $(1,2,3, \ldots)$

Kriteria penilaian sebagai berikut:

NPV $>0 \quad$ : Usaha franchiseO'Chicken yang diusahakan dikatakan layak/untung

NPV $<0 \quad$ : Usaha franchiseO'Chicken yang diusahakan dikatakan tidak layak/rugi

$\mathrm{NPV}=0 \quad$ : Usaha franchiseO'Chicken yang diusahakan berada pada titik impas

\section{b. Internal Rate of Return (IRR)}

Nilai Internal Rate of Return (IRR) digunakan untuk mengetahui tingkat keuntungan bersih atau investasi yang dilakukan dalam usaha franchiseO'Chicken. Internal Rate of Return (IRR) dapat dihitung menggunakan rumus berikut:

Dimana:

$$
\mathrm{IRR}=\mathrm{i}_{1}+\left[\frac{N P V_{1}}{N P V_{1}-N P V_{2}}+\left(i_{2}-i_{1}\right)\right]
$$

$$
\begin{array}{ll}
\mathrm{NPV}_{1} & =\text { Nilai NPV positif } \\
\mathrm{NPV}_{2} & =\text { Nilai NPV negative } \\
\mathrm{i}_{1} & =\text { Tingkat Compound rate yang menghasilkan NPV positif } \\
\mathrm{i}_{2} & =\text { Tingkat Compound rate yang menghasilkan NPV negatif }
\end{array}
$$

Kriteria penilaian sebagai berikut :

IRR $>\mathrm{r} \quad$ : Usaha franchiseO'Chicken yang diusahakan dikatakan layak/untung

IRR $<\mathrm{r} \quad$ : Usaha franchiseO'Chicken yang diusahakan dikatakan tidak layak/ rugi

IRR $=\mathrm{r} \quad$ : Usaha franchiseO'Chicken yang diusahakan berada pada titik impas

\section{c. Net Benefit Cost Ratio (B/C Ratio)}

NetBenefit Cost Ratio (B/C Ratio) adalah nilai perbandingan antara jumlahpresent value yang bernilai positif (pembilang) dengan present value yang bernilai negatif (penyebut). $\mathrm{Net} \mathrm{B} / \mathrm{C}$ ratio menunjukkan besarnya tingkat tambahan manfaat pada setiap tambahan biaya sebesar satu rupiah. Proyek dinyatakan layak untuk dilaksanakan apabila nilai B/C ratio lebih dari satu. Secara sistematis dapatdirumuskan sebagai berikut :

Dimana:

Net B/C Ratio $=\frac{\sum_{t-1}^{n} N B_{1}(+)}{\sum_{t-1}^{n} N B_{1}(-)}-\frac{\sum_{t-1}^{n}\left(B_{t}-C_{t}\right) /(1+i)^{t}(+)}{\sum_{t-1}^{n}\left(B_{t}-C_{t}\right) /(1+i) t(-)}$

$\mathrm{NB} \quad=$ Net benefit usaha

$\mathrm{Bt} \quad=$ Pendapatan kotor pada tahun i (Rp/tahun)

$\mathrm{Ct} \quad=$ Biaya usaha pada tahun $\mathrm{i}(\mathrm{Rp} / \mathrm{tahun})$

$\mathrm{i}=$ Compound rate atau tingkat bunga yang berlaku di daerah penelitian

$\mathrm{n} \quad=$ Umur usaha franchiseO'Chicken

$\mathrm{t} \quad=$ Tahun $(1,2,3)$

Kriteria penilaian sebagai berikut:

Net $\mathrm{B} / \mathrm{C}>1$ : Usaha franchiseO'Chicken yang diusahakan dikatakan layak/untung Net $\mathrm{B} / \mathrm{C}<1$ : Usaha franchiseO'Chicken yang diusahakan dikatakan tidak layak/rugi Net $\mathrm{B} / \mathrm{C}=1$ : Usaha franchiseO'Chicken yang diusahakan berada pada titik impas

\section{d. Pay Back Period (PBP)}


Pay Back Period (PBP) adalah jangka waktu tertentu yang menunjukkan terjadinya arus penerimaan (cash in flow) secara kumulatif sama dengan jumlah investasi dalam bentuk present value. Pay Back Period dapat dihitung dengan rumus:

Dimana:

$$
\mathrm{PBP}=\mathrm{T}_{\mathrm{P}-1}+\frac{\sum_{\mathrm{i}-1}^{\mathrm{n}} \mathrm{I}-\sum_{\mathrm{i}-1} \overline{\mathrm{B}}_{\mathrm{iep}-1}}{\overline{\mathrm{B}}_{\mathrm{p}}}
$$

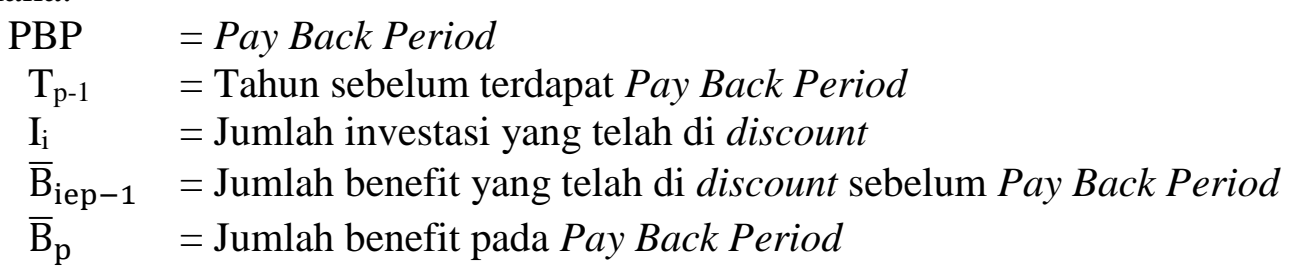

Kriteria penilaian :

- $\quad$ Semakin besar nilai Pay Back Period, semakin lama pengembalian investasi yang ditanamkan pada usaha franchise $O^{\prime}$ Chicken

- Semakin kecil nilai Pay Back Period, semakin cepat pengembalian investasi yang ditanamkan pada usaha franchise O'Chicken

\section{Analisis Sensitivitas (Switching Value)}

Analisis kepekaan atau analisis sensitivitas merupakan analisis yang digunakan untuk melihat dampak dari suatu keadaan yang berubah-ubah terhadap suatu analisis kelayakan dengan mengubah variabel - variabel resiko yang dianggap penting dalam suatu usaha. Analisis sensitivitas akan melihat apa yang akan terjadi dengan hasil kegiatan suatu usaha, jika terjadi perubahan - perubahan dalam dasar - dasar perhitungan biaya dan manfaat. Analisis switching value digunakan untuk mengetahui tingkat perubahan harga bahan baku dan penurunan volume penjualan, sehingga keuntungan mendekati normal yaitu NPV sama dengan nol.

\section{HASIL DAN PEMBAHASAN}

\section{A. Analisi Kriteria Investasi}

Net present value (NPV)

Net Present Value (NPV) merupakan nilai sekarang dari selisih antara benefit (manfaat) dengan cost (biaya) pada discount tertentu dengan menggunakan SocialOppourtunity of Capital (SOCC) sebagai Discount Factor (DF) (Pasaribu, 2012). Nilai Net Present Value (NPV) dapat dinyatakan bahwa usaha Franchise O'Chicken Jalan Utama Kelurahan Simpang Tiga ini layak dilaksanakan karena NPV yang diperoleh dari perhitungan kriteria investasi lebih besar dari nol (positif).

Bersarkan Tabel 1. Diperoleh nilai Net Present Value (NPV) sebesar Rp.883.637.518,menunjukkan bahwa dengan tingkat pengembalian bunga (discount factor) sebesar $12 \%$. usaha ini 
memberikan manfaat bersih sebesar Rp.7.363.646,- per bulanselama umur usaha 10 tahun menurut nilai mata uang sekarang.

Tabel 1. Perhitungan net present value (NPV) usaha franchise O'Chicken.

\begin{tabular}{crrr}
\hline & \multicolumn{1}{c}{ Tahun } & Net Benefit (Rp) & Present Value12\% (Rp) \\
\hline 1 & 2018 & $(420.521 .668)$ & $(375.465 .775)$ \\
2 & 2019 & 65.346 .409 & 52.093 .757 \\
3 & 2020 & 88.360 .212 & 62.893 .053 \\
4 & 2021 & 164.414 .702 & 104.488 .516 \\
5 & 2022 & 205.883 .852 & 116.824 .027 \\
6 & 2023 & 303.526 .386 & 153.775 .913 \\
7 & 2024 & 273.515 .108 & 123.724 .344 \\
8 & 2025 & 498.889 .846 & 201.493 .242 \\
9 & 2026 & 575.843 .834 & 207.655 .059 \\
10 & 2027 & 733.462 .772 & 236.155 .383 \\
\hline
\end{tabular}

\section{Net Benefit Cost Ratio (Net B/C)}

Net Benefit Cost Ratio dilakukan untuk mengukur berapa beasar manfaat yang dapat diterima dari setiap investasi yang di keluarkan. Net Benefit Cost Ratio diperoleh dari perbandingan Present Value positif dengan total Present Value negatif (Ibrahim, 2009). Tabel 2. menunjukkan hasil dari perbandingan antara present value positif dengan present negatif pada discount factor $12 \%$ nilai Net B/C diperoleh nilai sebesar 3,35 hal ini berarti setiap tambahan sebesar Rp.1 dapat menghasilkan sebesar Rp.3,35 dan pengusaha memperoleh keuntungan bersih sebesar Rp.3,35 dan dilihat dari perhitungan Net B/C usaha ini layak dijalankan dengan indikator nilai Net B/C lebih besar dari satu $(\mathrm{Net} B / \mathrm{C}>1)$.

Tabel 2. Net benefit cost ratio (Net B/C) usaha franchise O'Chicken

\begin{tabular}{crrr}
\hline & Tahun & Net Benefit (Rp) & Present Value at DF 12\% (Rp) \\
\hline 1 & 2018 & $(420.521 .668)$ & $(375.465 .775)$ \\
2 & 2019 & 65.346 .409 & 52.093 .757 \\
3 & 2020 & 88.360 .212 & 62.893 .053 \\
4 & 2021 & 164.414 .702 & 104.488 .516 \\
5 & 2022 & 205.883 .852 & 116.824 .027 \\
6 & 2023 & 303.526 .386 & 153.775 .913 \\
7 & 2024 & 273.515 .108 & 123.724 .344 \\
8 & 2025 & 498.889 .846 & 201.493 .242 \\
9 & 2026 & 575.843 .834 & 207.655 .059 \\
10 & 2027 & 733.462 .772 & 236.155 .383 \\
\hline \multicolumn{2}{c}{} & 2.488 .721 .452 & 883.637 .518 \\
\hline
\end{tabular}

175 | Analisis Kelayakan Finansial Usaha Franchise O'chicken Di Kelurahan Simpang Tiga Kecamatan Bukit Raya Kota Pekanbaru 


\begin{tabular}{cr}
\hline Jumlah Present Value Positif & 1.259 .103 .294 \\
\hline Jumlah Present Value Negatif & $(375.465 .775)$ \\
\hline Net B/C & 3,35 \\
\hline
\end{tabular}

\section{Internal Rate of Return (IRR)}

Internal Rate of Return merupakan suatu tingkat discount rate yang menghasilkan net present value sama dengan nol. Dengan demikian apabila hasil perhitungan IRR lebih besar dari Social Opportunity Cost of Capital (SOCC) dikatakan proyek tersebut layak untuk diteruskan, bila sama dengan SOCC berarti proyek berada pada break event point dan jika kecil dari SOCC maka proyek tersebut tidak layak untuk diteruskan (Ibrahim, 2009).

Tabel 3. Perhitungan net present value (NPV) pada tingkat bunga 35\% dan $40 \%$

\begin{tabular}{rrrrr}
\hline \multicolumn{2}{c}{ Tahun } & Net Benefit (Rp) & Present Value at DF 35\% (Rp) & Present Value at DF 40\% (Rp) \\
\hline 1 & 2018 & $(420.521 .668)$ & $(311.497 .532)$ & $(300.372 .620)$ \\
2 & 2019 & 65.346 .409 & 35.855 .368 & 33.340 .004 \\
3 & 2020 & 88.360 .212 & 35.913 .311 & 32.201 .243 \\
4 & 2021 & 164.414 .702 & 49.500 .043 & 42.798 .496 \\
5 & 2022 & 205.883 .852 & 45.914 .879 & 38.280 .897 \\
6 & 2023 & 303.526 .386 & 50.141 .098 & 40.311 .433 \\
7 & 2024 & 273.515 .108 & 33.469 .170 & 25.946 .876 \\
8 & 2025 & 498.889 .846 & 45.220 .412 & 33.804 .956 \\
9 & 2026 & 575.843 .834 & 38.663 .468 & 27.870 .990 \\
10 & 2027 & 733.462 .772 & 36.478 .787 & 25.356 .991 \\
\hline \multicolumn{2}{c}{ Jumlah } & 2.488 .721 .452 & 59.659 .004 & $(460.733)$ \\
\hline
\end{tabular}

Tabel 3. menunjukkan Nilai NPV positif berada pada tingkat suku bunga 35\% dengan nilai NPV sebesar Rp.59.659.004,-, pada tingkat suku bunga 40\% nilai NPV negatif sebesar Rp.(460.733,-). Perhitungan kedua NPV menghasilkan nilai IRR usahatani jeruk siam sebesar $40 \%$, artinya pada saat tingkat suku bunga 40\% NPV mendekati nol dan pada tingkat bunga tersebut usaha Franchise O'Chicken masih bisa melakukan pengembalian terhadap investasi yang dikeluarkan karena nilai IRR lebih besar dari SOCC, yaitu $12 \%$.

\section{Pay Back Period (PBP)}

Pay Back Period (PBP) adalah jangka waktu tertentu yang menunjukkan terjadinya arus penerimaan (cash in flow) secara kumulatif sama dengan jumlah investasi dalam bentuk present value. Semakin cepat dalam pengembalian biaya investasi sebuah proyek. maka semakin baik poyek tersebut karena semakin lancar perputaran modal. Hasil perhitungan Pay back Periodfranchise O'Chicken ini akan mencapai titik pengembalian investasi pada saat usaha berumur empat tahun tiga bulan yang artinya bahwa untuk jangka pengembalian modal awal saat pendirian usaha dengan umur usaha selama 10 tahun berada ketika usaha sudah berjalan selama empat tahun tiga bulan. 
Tabel 4. Perhitungan payback period (PBP) usaha franchise O'Chicken

\begin{tabular}{|c|c|c|c|}
\hline \multicolumn{2}{|c|}{ Tahun } & Net Benefit (Rp) & Present Value $12 \%(\mathrm{Rp})$ \\
\hline 1 & 2018 & $(420.521 .668)$ & $(375.465 .775)$ \\
\hline 2 & 2019 & 65.346 .409 & 52.093 .757 \\
\hline 3 & 2020 & 88.360 .212 & 62.893 .053 \\
\hline 4 & 2021 & 164.414 .702 & 104.488 .516 \\
\hline 5 & 2022 & 205.883 .852 & 116.824 .027 \\
\hline 6 & 2023 & 303.526 .386 & 153.775 .913 \\
\hline 7 & 2024 & 273.515 .108 & 123.724 .344 \\
\hline 8 & 2025 & 498.889 .846 & 201.493.242 \\
\hline 9 & 2026 & 575.843 .834 & 207.655 .059 \\
\hline 10 & 2027 & 733.462 .772 & 236.155 .383 \\
\hline Jumlah & & 2.488 .721 .452 & 883.637 .518 \\
\hline PBP & & & 4,3 \\
\hline
\end{tabular}

Berdasarkan Tabel 4. Menunjukkan hasil nilai kriteria investasi di atas menjelaskan bahwa usaha franchise O'Chicken di Kelurahan Simpang Baru layak untuk dijalankan dan dikembangkan karena nilai NPV > 0 yaitu Rp.883.637.518,- atau sama dengan Rp.7.363.645,-per bulan selama umur proyek, Net B/C > 1 yaitu 3,39, nilai IRR > SOCC yaitu 40\% dan nilai PBP lebih kecil dari umur proyek yaitu 4 tahun 3 bulan.

Tabel 5. Nilai kriteria investasi usaha franchise O'chicken periode 2018-2027

\begin{tabular}{lr}
\hline \multicolumn{2}{c}{ Kriteria Investasi } \\
\hline Net Present Value (NPV) & Nilai \\
Net Benefit Cost Ratio (Net B/C) & 3,35 \\
Internal Rate of Return (IRR) & $40 \%$ \\
Pay Back Period (PBP) & 4 Tahun 3 Bulan \\
\hline
\end{tabular}

\section{B. Analisis Sensitivitas}

Analisis sensitivitas berguna untuk mengkaji sejauh mana perubahan unsur-unsur dalam aspek finansial ekonomi berpengaruh terhadap keputusan yang dipilih (Soeharto. 2002). Analisis sensitivitas ini juga bertujuan untuk menilai. apa yang akan terjadi terhadap analisis kelayakan suatu usaha apabila terjadi perubahan di dalam perhitungan biaya (cost) atau manfaat (benefit).Pada penelitian ini, analisis switching value yang dilakukan adalah dengan menghitung perubahan maksimum yang dapat terjadi akibat kenaikan harga bahan baku dan penurunan skala produksi.

\section{Analisis sensivitas terhadap penurunan skala produksi}

Produksi sangat mempengaruhi tingkat penerimaan suatu usaha. semakin besar tingkat produksi maka total penerimaan akan semakin besar begitu pula sebaliknya jika produksi menurun maka total 
penerimaan akan semakin menurun. Analisis ini akan dilakukan dengan melihat tingkat penurunan skala produksi sampai usaha berada pada nilai NPV sama dengan nol.

Tabel 6. Analisis sensitivitas pada penurunan skala produksi

\begin{tabular}{crrr}
\hline \multirow{2}{*}{ Penurunan Skala Produksi (\%) } & NPV (Rp) & Net B/C (Rp) & IRR (\%) \\
\hline Normal & 883.637 .518 & 3,35 & $40 \%$ \\
$11,21 \%$ & 0 & 1,00 & $12 \%$ \\
\hline
\end{tabular}

Tabel 2 menunjukkan bahwa setelah dilakukan perhitungan analisis sensitivitas terhadap penurunan skala produksi dengan menggunakan cara trial and error. usaha franchise O'Chicken berada pada NPV sama dengan nol apabila terjadi penurunan skala produksi sama sebesar 11,21\% dengan harga jual tetap. Nilai NPV sama dengan nol. maka selama periode 10 tahun umur usaha pengusaha tidak untung dan tidak rugi. Analisis sensitivitas ini menunjukkan bahwa apabila terjadi penurunan skala produksi sebesar 11,21\% usaha franchise O'Chicken akan berada pada titik impas. apabila terjadi penurunan skala produksi lebih besar dari 11,21\% maka usaha franchise O'Chicken akan mengalami kerugian dan sebaliknya apabila terjadi penurunan skala produksi dibawah $11,21 \%$ maka usaha franchise O'Chicken masih dapat memperoleh keuntungan.

\section{Analisis sensitivitas terhadap perubahan harga input}

Harga input dalam analisis sensitifitas ini yang diubah meliputi harga daging ayam organik karena danging ayam organik merupakan bahan baku utama dalam kegiatan produksi usaha franchise O'Chicken dan apabila terjadi kenaikan harga pada bahan baku utama maka sangat berpengaruh benefit yang akan diperoleh dalam usaha ini. Pada analisis ini akan dilakukan anilisis terhadap kenaikan kenaikan harga bahan baku daging ayam organik sehingga nilai NPV sama dengan nol, karena nilai NPV sama dengan nol maka usaha tersebut tidak untung secara finansial.

Tabel 7. Analisis sensitivitas pada kenaikan harga input

\begin{tabular}{|c|c|c|c|}
\hline Perubahan Harga Input (\%) & NPV (Rp) & Net B/C & $\operatorname{IRR}(\%)$ \\
\hline
\end{tabular}

178 | Analisis Kelayakan Finansial Usaha Franchise O'chicken Di Kelurahan Simpang Tiga Kecamatan Bukit Raya Kota Pekanbaru 


\begin{tabular}{lrrr}
\hline $31,60 \%+$ & 0 & 1.00 & $12 \%$ \\
Normal & 883.637 .518 & 3,35 & $40 \%$ \\
\hline
\end{tabular}

Tabel 3. menunjukkan analisis sensitivitas terhadap peningkatan harga input dengan menggunakan cara trial and error sebesar 30,68\% persen, maka nilai NPV berubah menjadi Rp.0.-Apabila terjadi perubahan harga yaitu kenaikan input sebesar 30,68\% dangan biaya lain tetap, harga produk tetap, dan jumlah produksi tetap yang artinya usaha franchise O'Chicken mengalami titip impas. Analisis sensivitas ini mnyatakan bahwa apabila selama periode 10 tahun jika terjadi kenaikan harga ayam organik lebih besar dari 30,68\% maka usaha franchise O'Chicken ini dapat dikatakan akan mengalami kerugian dan sebaliknya jika kenaikan harga daging ayam organik dibawah 30,68\% usaha franchise O'Chicken masih memperoleh keuntungan.

\section{KESIMPULAN DAN SARAN}

\section{Kesimpulan}

Analisis aspek finansial usaha franchise O'Chicken di Kelurahan Simpang Tiga menunjukkan Hasil analisis kriteria investasi yang dilakukan dengan tingkat suku bunga sebesar $12 \%$ serta periode umur usaha 10 tahun diperoleh nilai NPV sebesar Rp.883.673.518,.-nilai IRR lebih tinggi dari discount rate yaitu sebesar $40 \%$, dan nilai $N e t$ B/C sebesar 3,35.Berdasarkan nilai-nilai tersebut dapat diartikan bahwa franchise O'Chickenyang dikembangkan oleh Bapak Makarius Anwar layak untuk dijalankan dan dikembangkan.

Hasil analisis sensivitas berdasarkan kenaikan harga input sebesar 31,60\% dan hasil analisis sensivitas berdasarkan penurunan produksi sebesar $11,21 \%$ usaha franchise O'Chicken akan berada pada titik impas. Apabila terjadi kenaikan kenaikan harga input dan penurunan produksi lebih besar dari angka tersebut maka usaha franchise O'Chicken ini dapat dikatakan akan mengalami kerugian dan usaha tersebut tidak dapat dilanjutkan.

\section{Saran}

Prospek usaha franchise O'Chicken Kecamatan Bukit Raya sangat potensial, namun upah tenaga kerja di usaha ini tidak sesuai dengan Upah Minimum Regional (UMR) kota pekanbaru. Sebaiknya disarankan pengusaha franchise O'Chicken di Jalan Utama ini untuk menambah upah tenaga kerja sesuai Upah Minimum Regional (UMR) kota pekanbaru yang mana mampu mendorong para tenaga kerja untuk meningkatkan prestasi dan produktivitas kerja..

\section{DAFTAR PUSTAKA}


Asrori, M.I. 2013. Analisis Kelayakan Finansial Usaha Agroindustri Tahu (Studi Kasus: Agroindustri Adi Jaya Tahu di Kelurahan Labuh Baru Barat Kecamatan Payung Sekaki Kota Pekanbaru). Skripsi Fakultas Pertanian Universitas Riau. Pekanbaru.

Badan Pusat Statistik. 2018. Pertumbuhan Ekonomi Indonesia. www.bps.go.id. Diakses 6 Juni 2018.

Benjamin, Gunawan. 2007. Pentingnya Pertumbuhan Ekonomi Yang Selaras Dengan Alam. Medan

Ibrahim Y. 2009. Studi Kelayakan Bisni Edisi Revisi. Rineka Cipta. Jakarta

Muchtar, et al. 2016. Bank dan Lembaga Keuangan Lain. Kencana. Jakarta

Mulyani, Umay. 2016. Skripsi Analisis Kelayakan Finansial Agroindustri Tahu (Studi Kasus Agroindustri Tahu Bapak Warijan di Desa Rambah Muda Kecamatan Rambah Hilir Kabupaten Rokan Hulu). Universitas Riau. Pekanbaru

Pasaribu, Ali Musa. 2012. Perencanaan Proyek \& Evaluasi Proyek Agribisnis. Lily Publisher. Makassar

Soeharto, I. 2002. Manajemen Proyek. Erlangga. Jakarta.

Suliyanto. 2010. Studi Kelayakan Bisnis Pendekatan Praktis. CV. Andi Offset. Yogyakarta.

Umar. 2003. Studi Kelayakan Bisnis. PT.Gramedia Pustaka Utama. Jakarta. 